\title{
Adoption of Open Source Software by Organizations - A Framework for Kenya
}

\author{
Charles M. Gichira \\ School of Computing and \\ Informatics, \\ University of Nairobi, Kenya
}

\author{
Andrew M. Kahonge \\ School of Computing and \\ Informatics, \\ University of Nairobi, Kenya
}

\author{
Evans K. Miriti \\ School of Computing and \\ Informatics, \\ University of Nairobi, Kenya
}

\begin{abstract}
Open Source Software (OSS) has emerged as an alternative to Closed Source Software in many fields of software usage. However, how and why OSS software is being adopted and implemented within organizations in Kenya is not well documented. This study attempts to advance this understanding. Survey and interview were used to explore and distinguish the types, level and factors determining adoption of OSS. The results obtained show that $60 \%$ of respondent organizations were adopting some form of OSS. OSS was preferred to CSS due to control over the software and the cost of acquiring and running the software. CSS was preferred due to quality of support from vendors, ease of use and fashion trend. Both were at par in terms of scalability, reliability, security features, functionality and integration with other systems.
\end{abstract}

\section{General Terms}

Software Adoption.

Keywords

Open Source Software, Diffusion, Adoption, Framework.

\section{INTRODUCTION}

Organizations worldwide are adopting OSS with the aim of reducing cost, avoiding vendor lock-in, and promoting common data [1].

While developing countries like Kenya lag behind in adoption of OSS and software usage in general, developed countries are ahead in adoption both in public and private countries. OSS products such as the Linux operating system, PHP, Apache Web servers, Perl, Mozilla Firefox web browser, MySQL database amongst others are becoming predominant OSS technologies in their respectful domains. There seems to be a trend to go OSS especially on software's that rely, use or are used across the internet. A good example is the case of Apache Web servers which is being used widely now. As of January 2012 the Apache market segment was $64.27 \%$ while the Microsoft server was only $15.66 \%$, followed by nginx with $8.54 \%$ and Google with $3.47 \%$. This growth trend has been increasing exponentially in the last 16 years [2].

Linux operating system is showing significance growth in open source software. Linux has gained a $1 \%$ market share in the client operating system market and a $27 \%$ market share in the server market [3].

OSS is also the software of preference within the Internet and high-performance computing [4]. In Kenya for example, there is a growing trend for cyber cafes and other publicly accessible businesses and organizations to adopt OSS.

\section{LITERATURE REVIEW}

Open Source Software refers to software whose source code is available to its users. It can be developed and maintained by individual programmers or companies, and it is usually available at no licensing cost. The source code can be used, revised, changed, expanded, and distributed without requiring permission or making payments to an external party [5].

In addition to Open source definition above one OSI insists that open-source software must comply with the following criterion [5]:

1. The license shall not restrict any party from selling or giving away the software or require a royalty or other fee for such sale.

2. The program must include source code, and allow distribution in source code as well as compiled form.

3. The license must allow modifications and derived works, and allow them distributed under the same terms.

4. The license may restrict source-code from being distributed in modified form.

5. No Discrimination against persons or groups.

6. The license must not restrict anyone from making use of the program in a specific field of endeavor.

7. Distribution of License - The rights attached to the program must apply to all to whom the program is redistributed.

8. License Must Not Be Specific to a Product.

9. License Must Not Restrict Other Software

10. License Must Be Technology-Neutral

\subsection{Types of Open Source Software}

\section{Licenses}

The main purpose of an OSS license is that the user must get both the access to source code and the right to make changes to the source code as they deem appropriate. In concerns to the redistribution of the software certain conditions apply depending on the type of license. An OSS license allows certain modification of the software, but depending on the license type, there may be additional conditions for the distribution, reuse, and modification of the software.

There are various different types of open source licenses. Among the most well-known and most frequently discussed in the literature are as follows.

The GNU General Public License (GPL or GNU GPL). The GPL is the typical example of an OSS license. It contains strong language about the freedom of software and the copyleft requirement that all derivative works also remain free. 
The Lesser General Public License Library (LGPL). The LGPL is a variant of the GPL license. The key difference between the GPL and LGPL licenses is that software or a library under the LGPL can be "linked to" or "used by" either a GPL-licensed or a proprietary program.

The Berkeley Software Distribution License (BSD). The BSD Licenses are considered the least restrictive of the OSS licenses. Under the BSD Licenses, distribution of source code is permitted, but not mandated for derivative works.

The alternative to OSS is proprietary software, also referred to as commercial, non-free, or closed source software. In this paper, proprietary software is defined as software having a license that typically restricts the copy, distribution and modification of the software. A proprietary license does not grant permission to access the source code, and it usually requires a royalty payment [6]. On the other hand, "Shareware" or "Freeware" is software provided under traditional proprietary license that prohibits access to source code or creation of derivative work. Shareware is typically provided free of charge during trial period. If the licensee desires to continue to use the shareware following the trial period, it must pay a license fee. "Freeware" does not require the payment of any license fee for use of the software [6].

Public domain software is generally provided without a license, with the developer relinquishing all copyrights that it may have in programming. Users can copy, modify, and distribute the software freely and generally have no obligation to give any attribution to the original developer [7].

\subsection{Open Source Software History}

OSS concept dates back to the 1950s, when computer programs were distributed freely with the source code. During the time, computer software was seen as mere algorithms and not as processes or machines [3]. Computer manufacturers distributed software free of charge as part of their customer service policy. This was until IBM, the leading computer manufacturer at the time, announced in June 1969 that the pricing of software would be separated from that of pricing hardware [3]. This 'unbundling' of software is seen as the starting point of the software industry. Computer software is recognized as a form of intellectual property.

Quoting Oxford English Dictionary Yuan defines Intellectual Property in his study as "intangible property that is a result of creativity, such as patents, copyrights, etc." [3]. Computer software fits this definition and is covered in most countries by some form of copyright law. Copyright is "the exclusive, legally secured right to publish, reproduce, and sell the matter and form of a literary, musical, dramatic or artistic work" [3].

\subsection{Diffusion and Adoption of Information Technology}

\subsubsection{Adoption of Technology}

Research into IT systems adoption has focused on both individual and organizational levels of adoption. The research into the individual level has focused mainly in theories of individual decision-making such as the Theory of Planned Behavior (TPB) [8], the Theory of Reasoned Action (TRA) [8], the Technology Acceptance Model (TAM) [9] and the Unified Theory of Acceptance and Use of Technology (UTAUT) [10]. These theories explain individuals' independent decisions in the adoption or rejection of technology.
In organizations, the decision to adopt a technological innovation is not undertaken by individual users but is instead most often taken by an authority figure, and individual employees are mandated to adopt the innovation [11]. Consequently, many of the above theories of individual adoption of technology are less suitable for explaining organizational IT adoption decisions as is our case [12]. Some of the cited organization adoption theories include;

Resource-based theory (RBT): In this theory, when an organization adopts and develop an innovation such as IS before its competitors and keeps it unknown to competition to avoid imitation, it gets a head-start and will be more successful than the competition [13]. Moreover, RBT states that the services that are rendered by a firm's unique bundle of resources and capabilities may lead to value creation [14].

Institutional theory: organizational decisions are not driven purely by rational goals of efficiency, but also by social and cultural factors and concerns for legitimacy. The theory claims that firms become more similar due to isomorphic pressures and pressures for legitimacy [15]. This means that firms in the same field tend to become homologous over time, as competitive and customer pressures motivate them to copy industry leaders. This theory suggests that organizations are forced to adopt an innovation by external pressures and thus all organizations and up looking the same in that aspect.

Diffusion of Innovation (DIO): is a theory of how, why, and at what rate new ideas and technology spread through cultures, operating at the individual and firm level. DOI theory sees innovations as being communicated through certain channels over time and within a particular social system [16].

Based on DOI theory at firm level, innovativeness is related to such independent variables as individual (leader) characteristics, internal organizational structural characteristics, and external characteristics of the organization (a) Individual characteristics describes the leader attitude toward change. (b) Internal characteristics of organizational structure includes observations according to Rogers whereby: "centralization is the degree to which power and control in a system are concentrated in the hands of a relatively few individuals"; "complexity is the degree to which an organization's members possess a relatively high level of knowledge and expertise"; "formalization is the degree to which an organization emphasizes its members' following rules and procedures"; "interconnectedness is the degree to which the units in a social system are linked by interpersonal networks"; "organizational slack is the degree to which uncommitted resources are available to an organization"; "size is the number of employees of the organization". (c) External characteristics of organizational refer to system openness [16]. While, DOI has been one of the most important theories for the understanding and framing of technology adoption in the IS research. It has been criticized for containing some deficiencies. For example, Rodgers claimed that the over emphasis on the innovation itself can make the innovation a presumption of the innovators success before it has even been applied and tested in the organization [16]. Tornatzky and Fleischer claimed that the adoption of innovation research has neglected market characteristics as an important variable to be studied [17]. They added that the processes of adoption of technology by organizations are very different from those by individuals.

Technology Organization Environment (TOE): is a fundamental approach to investigating a firm context that 
influences the process by which it adopts, implements, and diffuses technological innovations. The TOE framework identifies three aspects to firm decision-making behavior for technological innovations: technological context, organizational context, and environmental context.

Technological context includes both the internal and external technologies used by the firm. Meanwhile, organizational context refers to descriptive characteristics of the organization, including firm size and scope, complexity of firm managerial structure, and quality and degree of its human resources while environmental context refers to the firm industry and its dealings with trading partners, competitors and government [17].

\subsubsection{Stages in the Process of Technology \\ Adoption}

The adoption of IT systems by organizations is characterized by a set of well-defined stages with different characteristics in each stage. Rogers' presents (1) The Initiation phase consists in the entire information gathering, conceptualization and planning for the innovation. And (2) The Implementation phase includes all the events, actions, and decisions involved in putting the innovation into use [16] figure 1.

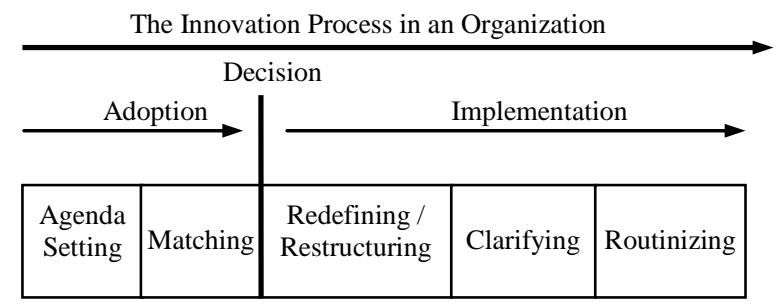

Fig 1. Five stages in the innovation process in organizations

There are several other studies on the adoption and implementation including; one by Cooper and Zmud (1990). It has six phases: Initiation, Adoption, Adaptation, Acceptance, Routinization and Infusion. Another framework of the adoption and implementation stages is presented by Tornatzky and Fleischer [17]. Their technology adoption framework, like the Cooper Zmud's, is based on six phases: 1) research; 2) development; 3) deployment; 4) adoption; 5) implementation; and 6) routinization (See Figure 2).

\begin{tabular}{|c|c|c|c|c|c|c|}
\hline \multicolumn{4}{|l|}{ DEVELOPING } & \multicolumn{3}{|c|}{ USING } \\
\hline ENVIRONMENT & & $\mathrm{D}$ & $\mathrm{D}$ & & $\begin{array}{l}\mathrm{I} \\
\mathrm{M} \\
\mathrm{P}\end{array}$ & $\begin{array}{l}\mathrm{R} \\
\mathrm{O}\end{array}$ \\
\hline FIRM & $\begin{array}{l}\mathrm{R} \\
\mathrm{E} \\
\mathrm{S}\end{array}$ & $\begin{array}{l}\mathrm{E} \\
\mathrm{V} \\
\mathrm{E} \\
\mathrm{L}\end{array}$ & $\begin{array}{l}\text { E } \\
P \\
\text { L }\end{array}$ & $\begin{array}{l}\mathrm{A} \\
\mathrm{D} \\
\mathrm{O}\end{array}$ & $\begin{array}{l}\mathrm{L} \\
\mathrm{E} \\
\mathrm{M}\end{array}$ & $\begin{array}{l}\mathrm{U} \\
\mathrm{T} \\
\mathrm{I} \\
\mathrm{N}\end{array}$ \\
\hline WORK GROUP & $\begin{array}{l}\text { E } \\
A \\
\text { R }\end{array}$ & $\begin{array}{l}\mathrm{O} \\
\mathrm{P} \\
\mathrm{M}\end{array}$ & $\begin{array}{l}\mathrm{Y} \\
\mathrm{M}\end{array}$ & $\begin{array}{l}\text { T } \\
\mathrm{T}\end{array}$ & $\begin{array}{l}\mathrm{E} \\
\mathrm{N} \\
\mathrm{T}\end{array}$ & $\begin{array}{l}\mathrm{I} \\
\mathrm{Z} \\
\mathrm{A}\end{array}$ \\
\hline PEOPLE & $\begin{array}{l}\mathrm{C} \\
\mathrm{H}\end{array}$ & $\begin{array}{l}\mathrm{E} \\
\mathrm{N} \\
\mathrm{T}\end{array}$ & $\begin{array}{l}\mathrm{E} \\
\mathrm{N} \\
\mathrm{T}\end{array}$ & $\mathrm{N}$ & $\begin{array}{l}\mathrm{T} \\
\mathrm{I} \\
\mathrm{O} \\
\mathrm{N}\end{array}$ & $\begin{array}{l}\mathrm{T} \\
\mathrm{I} \\
\mathrm{O} \\
\mathrm{N}\end{array}$ \\
\hline $\begin{array}{l}\text { Years to } \\
\text { (Per tech }\end{array}$ & & & & & $\begin{array}{l}\text { er co } \\
\text { Dec } \\
\text { er In }\end{array}$ & $\begin{array}{l}\text { nonths } \\
\text { pany) } \\
\text { les } \\
\text { istry) }\end{array}$ \\
\hline
\end{tabular}

Fig 2. Processes of technological innovation
This paper will focus on the innovation-adopters or users of technology rather than on the innovation-generators or developers of technology.

Another vital feature important to mention in this section is the Rogers' adopter classification. According to Rogers' adopters of technology can be classified as innovators (2.5\%), early adopters $(13.5 \%)$, early majority (34\%), late majority (34\%) and laggards (16\%).

\section{RESEARCH METHODOLOGY}

This section presents a proposed framework, based upon Tornatzky and Fleischer's [17] elements of technological innovation. From the review of the literature above, several factors that appear to facilitate or inhibit the adoption of OSS in organizations emerge. We have organized these themes into a framework based on Tornatzky and Fleischer's [17] work. The proposed framework is only used to map elements.

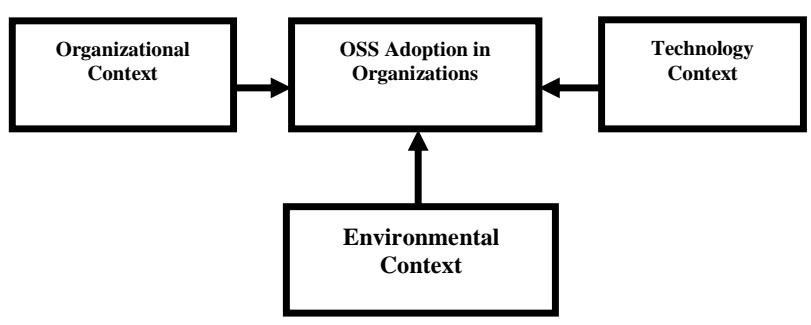

Fig 3. Conceptual Framework to Investigate OSS Adoption by organizations

\subsection{Organizational Context}

Organizational context is a set of measures or characteristics of an adopting organization that facilitates or constrains the adoption and implementation of innovation. Organizational context refers to descriptive measures about the organization such as scope, size, and managerial structure of the organization that influence the adoption decision [17]. The following are the hypothesis in the organizational context:

H1: Top management support: Supportive management and especially the CEO promote adoption of OSS. This include issues such as deciding whether adoption is mandatory or voluntary, providing training and support, hiring new employees or consultants to act as mentors, and championing the OSS adoption initiative [18].

H2: Cost: Low total cost of ownership promotes adoption of OSS. In the long run, lower licensing cost become increasingly significant, and the adopting organization can find OSS adoption to be efficient and [18].

H3: Managerial innovativeness: This is the degree to which an organization is willing to take risks and is actively considering the introduction of new technologies. Thus, innovative management enhances the adoption of OSS [18].

H4: Technical expertise of IT staff: Lack of IT personnel capable of supporting OSS IS hinders adoption of OSS.

H5: Crusaders: Presence of an OSS crusader in top management or ICT department enhances adoption of OSS.

H6: Proprietary lock-in: Lock-in on proprietary software hinders adoption of OSS.

H7: Internet access: Internet access enhances OSS adoption. 
H8: Organizational changes: Willingness to carry out organizational changes enhances probability of adoption.

\subsection{Technology Context}

The technology context is described as the internal as well as the external technologies available to the organization. The following factors emerged as core hypothesis: [18]

H9: Interoperability between systems: lack of interoperability with some major CSS inhibits adoption of OSS.

H10: Perceived reliability of OSS: The perceived reliability enhances adoption of OSS.

H11: Perceived security of OSS: The perceived better security preventing OSS from virus attacks, spam, etc, enhances adoption of OSS.

H12: Perceived usability difficulty of OSS: The perceived difficulty on usability hinders the adoption of OSS

H13: Perceived satisfaction with current non-OSS systems: Dissatisfaction with existing non-OSS technologies ranging from prices to product quality enhances adoption of OSS.

H14: Customization and extensibility: Access to the source code to customize, extend, add, and modify an existing function enhance adoption of OSS.

H15: Scalability: Scalability of OSS enhances its adoption.

H16: Functionality: Availability of more functions on OSS enhances adoption.

\subsection{Environmental Context}

The environmental context is the place where an organization conducts its business. The following are hypothesis based on the environmental context:

H17: Lack of widespread use in the organizations: The lack of many organizations adopting of OSS hinders OSS adoption.

H18: Government support: Lack of Government policy support and OSS usage hinders the adoption of OSS.

H19: Availability of external support services: Lack of well established vendors who support OSS hinders adoption of OSS in Kenya.

H20: Lack of OSS awareness by organizations: that OSS can be alternative to proprietary software's they are using hinders OSS hinders adoption.

H21: Piracy: Widespread piracy of CSS hinders adoption of OSS.

H22: Marketing: Lack of aggressive marketing hinders adoption of OSS.

H23: Education system: Lack of adequate training in and early introduction to OSS hinders its adoption.

H24: Fashion trend: Fashion trend makes what is expensive to appear more fashionable hence hindering adoption of OSS.

\subsection{Research Methodology Choice}

A qualitative research approach is used in this research to explore the extent of OSS adoption in organizations as well as to investigate the factors influencing or inhibiting OSS adoption. The qualitative research approach of this study is explained by the fact that, there are few existing conceptual frameworks to guide a research effort in this area. For these reasons, a qualitative research perspective was selected over a confirmatory or causal research design approach. In order to generate data, two collection methods are used in this research; questionnaire surveys, and interviews.

The target population for the study consists of IT Managers who are generally persons in charge of ICT in the organizations. Nairobi was selected because it is one of the most diverse areas in the Kenya, when it comes to socioeconomic, political, and cultural issues. The presence of the government headquarters, a highly educated workforce, rapidly growing population trends and the development of the local technology hub for the region in this area provide a good ground for the kind of research. In addition, Nairobi region is rapidly growing in industries. The following are the five research goals developed in this study:

1. Identify the organizations using OSS and their characteristics.

2. To identify the types and names of OSS products and the extent of their adoption in organization.

3. To identify the factors behind OSS adoption in organizations.

4. To identify the future plans for the adoption of OSS in the organizations.

5. To identify the inhibiting factors behind the nonadoption of OSS in the organizations.

A survey was used on the first two and interview for the last three.

\section{FINDINGS AND ANALYSIS}

Pre-test of the questionnaire was conducted prior to it being sent out to help ensure the questions were worded properly. The use of multiple items to measure the same construct was another technique used. The averaging of uniqueness of the individual items help make finer distinctions between organizations and have higher reliability [19].

\subsection{Reliability Analysis}

This study used a Cronbach Alpha reliability coefficient to check for internal consistency and reliability of the independent and dependent variables.

\subsection{Internal Consistency}

According to Al-somali, the assessment of the Cronbach alpha score tests the correlation of the variable items, determining the internal consistency of the questionnaire items. Items that do not correlate can be dropped on the basis of their item/total correlation. A low inter-item correlation should be deleted to see if the item's removal improves the Cronbach alpha score, thereby increasing the reliability of the measure. A Cronbach alpha score over 0.7 indicates that items measuring the variable hold together well and is the recommended level in a preliminary research study [19]. The research uses the above approach to carry out the reliability tests for the research variables.

\subsection{Content Validity}

The assessment of this appropriateness is referred to as the 'content validation' or face validation [3]. This study used IT personnel with IS industry experience along with the supervisor to pre-test the content validity.

\subsection{Internal Validity}

Internal validity error is concerned with whether changes in the dependent variable are actually caused by the independent variable or whether another variable, such as an intervening variable, is confounding the relationship. Information Systems researchers without experimental control should try to justify internal validity [21]. 


\subsection{Hypothesis Testing}

In hypothesis testing it is important that the appropriate statistical test is used and the significance level is considered [21]. Multiple regression is considered appropriate for testing associations between the independent variables and the dependent variables.

\subsection{Multiple Regression}

Regression is a technique for measuring the linear association between a dependent variable and a set of the independent variables [19]. Multiple regression is a method of analyzing the changes in dependent variable, by using a set of independent variables, in order to predict the mean value of the dependent variable on the basis of the known values of the independent variable.

In the research, regression is used to determine the degree of influence of the independent constructs (Organizational Factors, IT Factors and Environment Factors) on the dependent construct, 'The Use of Open Source Software in the organization'. When using a statistical test such as multiple regression, the level of significance at which the research model will be tested is important.

\subsection{Tests of Significance}

The level of significance at which the null hypothesis is tested indicates the probability of accepting or rejecting the idea that chance caused the results [3]. The accepted level of significance for rejecting the null hypothesis is by convention is 0.05 level [21]. The research adopts the convention.

\subsection{Use of Open Source Software}

The respondents were asked to indicate whether they have adopted OSS and if they have what OSS they have adopted. 60 percent of the respondents acknowledge that they were using open source software at some level within their organization (Figure 4).

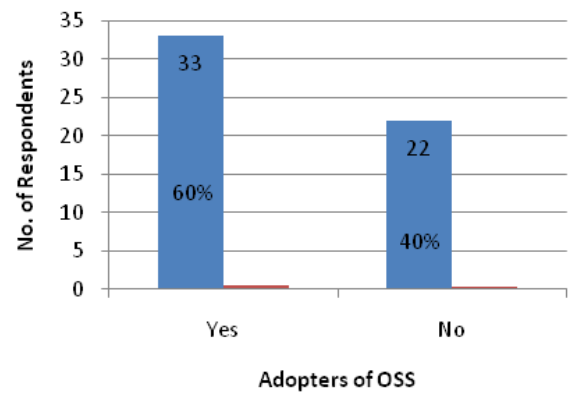

Fig 4. OSS Adoption

$40 \%$ of the adopters have adopted General Purpose OSS, 33\% have adopted Domain Specific OSS while $27 \%$ have adopted both General Purpose and Domain Specific.

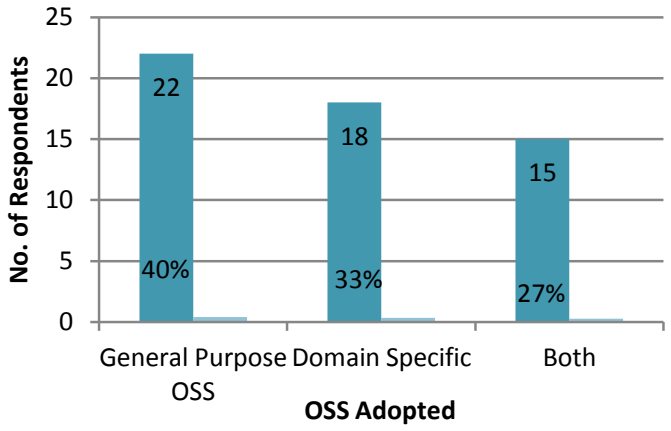

Fig 5. Type of OSS Adopted

Table 1. Names of OSS Adopted

\begin{tabular}{|c|c|c|c|}
\hline & Open Source Name & Adopters/55 & $\begin{array}{l}\text { Percentage } \\
\text { adoption }\end{array}$ \\
\hline 1 & Apache & 28 & $51 \%$ \\
\hline 2 & MySQL & 27 & $49 \%$ \\
\hline 3 & Mozilla Firefox & 23 & $42 \%$ \\
\hline 4 & Apache & 23 & $42 \%$ \\
\hline 5 & PHP & 18 & $33 \%$ \\
\hline 6 & OpenOffice.org & 17 & $31 \%$ \\
\hline 7 & Linux & 17 & $31 \%$ \\
\hline 8 & GNOME & 8 & $15 \%$ \\
\hline 9 & Open Office & 8 & $15 \%$ \\
\hline 10 & Firewall Builder & 8 & $15 \%$ \\
\hline 11 & $\mathrm{KDE}$ & 7 & $13 \%$ \\
\hline 12 & Joomla & 7 & $13 \%$ \\
\hline 13 & PostgreSQL & 5 & $9 \%$ \\
\hline 14 & Perl & 5 & $9 \%$ \\
\hline 15 & GGLCROM & 3 & $5 \%$ \\
\hline 16 & Xayara & 3 & $5 \%$ \\
\hline 17 & CYBOP & 3 & $5 \%$ \\
\hline 18 & GNOME Office & 2 & $4 \%$ \\
\hline 19 & VNC Viewer & 2 & $4 \%$ \\
\hline 20 & J-BOSS & 2 & $4 \%$ \\
\hline 21 & Plone & 2 & $4 \%$ \\
\hline 22 & SugarCRM & 2 & $4 \%$ \\
\hline 23 & SQLITE & 1 & $2 \%$ \\
\hline 24 & FITEBIRD & 1 & $2 \%$ \\
\hline 25 & Koffice & 1 & $2 \%$ \\
\hline 26 & ThinerBird & 1 & $2 \%$ \\
\hline 27 & $\mathrm{Nvu}$ & 1 & $2 \%$ \\
\hline 28 & Daisy & 1 & $2 \%$ \\
\hline 29 & DRUPAL & 1 & $2 \%$ \\
\hline 30 & DJANGO & 1 & $2 \%$ \\
\hline 31 & Opensignature & 1 & $2 \%$ \\
\hline 32 & OPENPGP & 1 & $2 \%$ \\
\hline 33 & OpenEJB & 1 & $2 \%$ \\
\hline 34 & Geronimo Oscar & 1 & $2 \%$ \\
\hline 35 & GCC & 1 & $2 \%$ \\
\hline 36 & IREPRTS & 1 & $2 \%$ \\
\hline
\end{tabular}




\subsection{Cronbach Coefficient Alpha}

The Cronbach Coefficient Alpha is a measure of consistency and reliability of a set of variables. Generally, the higher the Cronbach Alpha, the more reliable the test is. There isn't a commonly agreed cut-off, but generally, a score above 0.7 is acceptable [22].

Table 4.5: Information Technology Reliability Statistics

\begin{tabular}{|l|l|l|}
\hline & $\begin{array}{l}\text { Cronbach's } \\
\text { Alpha Based on } \\
\text { Standardized } \\
\text { Items(a) }\end{array}$ & \\
Alpha(a) & .779 & N of Items \\
\hline 1.159 & 18 \\
\hline
\end{tabular}

Table 4.6: Organizations Reliability Statistics

\begin{tabular}{|l|l|l|}
\hline & $\begin{array}{l}\text { Cronbach's } \\
\text { Alpha Based on } \\
\text { Standardized } \\
\text { Cronbach's } \\
\text { Alpha }\end{array}$ & N of Items \\
\hline .878 & .886 & 4 \\
\hline
\end{tabular}

Table 4.7: Environmental Reliability Statistics

\begin{tabular}{|l|l|l|}
\hline & $\begin{array}{l}\text { Cronbach's } \\
\text { Alpha Based on } \\
\text { Standardized } \\
\text { Cronbach's } \\
\text { Alpha(a) }\end{array}$ & N of Items \\
\hline .688 & .623 & 10 \\
\hline
\end{tabular}

The Cronbach Coefficient Alpha score for each of the 3 groups were recomputed. The Cronbach Alpha scores for Group 1 (Information Technology Factors), Group 2 (Organizational Factors) and Group 3 (Environmental Factors) are $0.779,0.886$ and 0.623 respectively.

\subsubsection{Hypothesis Testing}

In this section we present the results of the hypothesized relationship between the independent variables (Organization, Information Technology, and Environmental) and the dependent variable (Use of Open Source Software).

\subsubsection{Multiple regression analysis}

Multiple regression analysis was used to test the research hypotheses. Following statistical convention, the null hypothesis was tested and the rejection of the null hypothesis indicated support for the research hypothesis.

The first analysis was done using adoption of OSS question as the response variable, if an organization is already currently using open source software. Each of the 3 groups of predictor variables are used to model the response separately. It is found that the 3 groups of predictor variables have significant relationship to the response variable. Hence, it was concluded that there is some statistical evidence some of the factors are affecting the current form of software usage in the companies even though a large sample would give better result since this analysis works better with a sample of 400 or above data.

\subsubsection{T-Tests}

A one-sample t-test helps determine whether $\mu$ (the population means) is equal to a hypothesized value (the test mean). The test uses the standard deviation of the sample to estimate $\sigma$ (the population standard deviation). If the difference between the sample mean and the test mean is large relative to the variability of the sample mean, then $\mu$ is unlikely to be equal to the test mean.

A one-sample t-test is used when continuous data are available from a single random sample. The test assumes the population is normally distributed.

Table 1. Names of OSS Adopted

\begin{tabular}{|c|c|c|c|c|c|c|}
\hline & \multicolumn{6}{|c|}{ Test Value $=0$} \\
\hline & $\mathrm{t}$ & $\mathrm{df}$ & $\begin{array}{l}\text { Sig.(2- } \\
\text { tailed) }\end{array}$ & $\begin{array}{l}\text { Mean } \\
\text { Differ } \\
\text { ence }\end{array}$ & $\begin{array}{r}95 \% \mathrm{Cc} \\
\text { Interv } \\
\text { Diff }\end{array}$ & $\begin{array}{l}\text { fidence } \\
\text { of the } \\
\text { ence }\end{array}$ \\
\hline & Lower & Upper & Lower & Upper & Lower & Upper \\
\hline Scalability. & -.090 & 87 & .928 & -.034 & -.78 & .72 \\
\hline Reliability. & 1.063 & 87 & 291 & .398 & -.35 & 1.14 \\
\hline $\begin{array}{l}\text { Quality of } \\
\text { support from } \\
\text { vendors. }\end{array}$ & -2.250 & 87 & .027 & -.841 & -1.58 & -.10 \\
\hline $\begin{array}{l}\text { Security } \\
\text { features. }\end{array}$ & .931 & 87 & .355 & .364 & -.41 & 1.14 \\
\hline Ease of use. & -2.126 & 87 & .036 & -.773 & -1.50 & -.05 \\
\hline Functionality. & -.420 & 87 & .676 & -.148 & -.85 & .55 \\
\hline Fashion. & -2.192 & 87 & .031 & -.761 & -1.45 & -.07 \\
\hline $\begin{array}{lr}\text { Ability } & \text { to } \\
\text { give you } \\
\text { more control } \\
\text { over the } \\
\text { software. }\end{array}$ & 3.614 & 87 & .001 & $\begin{array}{l}1.27 \\
3\end{array}$ & .57 & 1.97 \\
\hline $\begin{array}{l}\text { Integration } \\
\text { with other } \\
\text { systems. }\end{array}$ & 1.811 & 87 & .074 & .659 & -.06 & 1.38 \\
\hline $\begin{array}{ll}\text { Cost } & \text { vs. } \\
\text { Benefits. }\end{array}$ & 3.589 & 87 & .001 & $\begin{array}{l}1.22 \\
7\end{array}$ & .55 & 1.91 \\
\hline
\end{tabular}

The responses to the determinants to adoption were coded so that any positive value implies that the company is in favor of open source software, and vice versa. The standard t-test is used to assess if the mean response to these questions are significantly different from 0 .

Results show that the mean response on; Quality of support, Ease of use, Fashion, control over the software and cost benefit factors are significant with a p-value $<0.05$.

Therefore we can conclude that companies prefer open source software over closed source software in terms of; control over 
the software and cost vs. benefit factors. Open source and closed source software are on par in terms of scalability, reliability, security features, functionality, and integration of systems. Closed source is better in terms of; quality of support from vendors, ease of use and fashion trends.

\subsubsection{Discussion of Findings}

From the demographics results $60 \%$ of the respondents acknowledge that they were using open source software at some level within their organization. This number is probably lower that the true figure as it is acknowledged than respondents may not be aware of every item of software used or the respondent may not know that some of the installed software is open source.

Both general purpose and domain specific Open Source Software were in use with more General Purpose OSS being used as compared to the domain specific OSS.

The respondents surveyed placed the highest importance on their choice for adopting open source software in the increased control open source software is able to deliver and cost benefit.

Analysis was used to assess if there are any difference in the reasons given for adopting open source software. Although most companies cite lower costs and more control as the more important reasons for adopting open source software, there is not enough statistical evidence to substantiate the claim that these two reasons are more compelling than the other reasons like unique functionality and higher reliability.

One possible assertion that could be made from the results of this study is that the current competitive climate of the industry in which the organizations operates places cost pressures upon IT departments. This causes IT departments to seek alternative means of delivering the same services to their respective organizations. The advantage mentioned in literature review of reduced cost and increase scalability that Open Source Software delivers appeals to such organizations.

\subsection{A Framework for Adoption of OSS by Organizations in Kenya}

A framework for adoption of OSS by organizations in Kenya based on our data will now be developed.

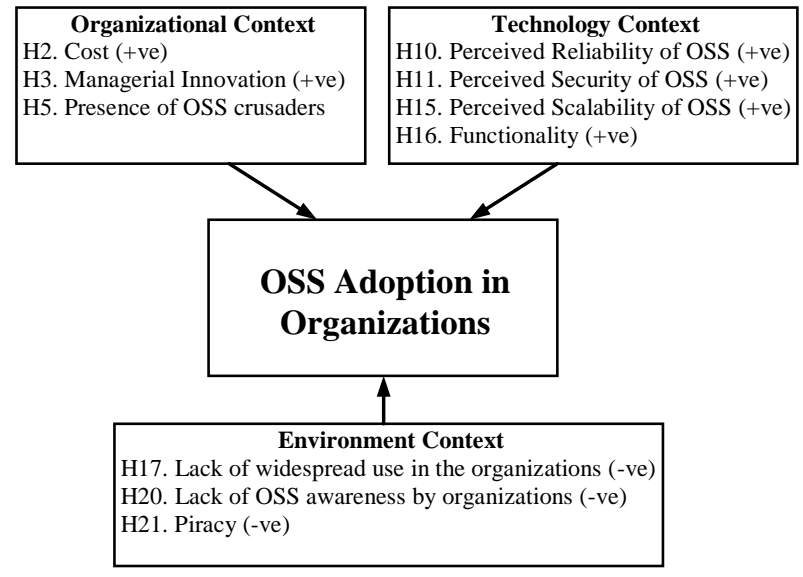

Fig 1. Deduced Organizational Context

The final framework shows that cost, innovativeness of management and presence of a crusader are organizational factors that enhances adoption, perceived reliability, security, scalability and functionality are information technology factors that facilitates OSS adoption, environmental factors deduced are factors that hinder adoption of OSS including lack of use in similar industries, lack of awareness and of piracy of Commercial Sourced Software.

\section{CONCLUSION}

Cost of acquisition and maintenance of software was found to be a motivation for adoption of OSS. The perception in terms of scalability, reliability, security features, functionality and integration of systems factors were perceived to be at par as reasons for adoption of OSS and CSS. This is an indication that OSS is growing in all those areas since it had been lagging behind previously. In terms of fashion, it seems that commercial software is still way ahead and it seems more fashionable to have CSS than OSS. The more expensive it is to acquire software seems to show that it is more fashionable. While corruption on acquisition of software was mentioned as a factor influencing OSS acquisition and adoption, the research did not find it to be a reason for lack of OSS adoption.

A number of respondents from the interviews noted that the lack of interoperability between systems and the lack of management support were reasons inhibiting adoption of OSS by organizations.

The findings from this research also indicated that cost factors are important but not a core, important category for organizations' IT managers when deciding to adopt OSS. The IT managers in our study were found to be more concerned about the quality, security and liability issues surrounding OSS than about the potential cost-benefit factors associated with the adoption and use of OSS.

This study also shows that most organizations are very conservative industry when it concerns adopting new technologies.

\section{REFERENCES}

[1] Fitzgerald, "A critical look at open source," IEEE Computer, July 2004.

[2] (2011, December) Web Server Survey. [Online]. http://news.netcraft.com

[3] E.K.K Yuan, "The adoption of Open Source Software by Singaporean Companies," 2009.

[4] P Kavanagh, Open Source Software: Implementation and Management. Amsterdam; Boston: Elsevier Digital Press, 2004.

[5] (2012, December) Open Source Initiative. [Online]. http://www.opensource.org/licenses/index.html

[6] F. Milano, Power System Modelling and Scripting., 2010.

[7] M. Overly, The Open Source Hand Book, 6th ed., 2003.

[8] I. Ajzen, The theory of planned behavior, Organizational Behavior and Human Decision Processes., 1991, vol. 50.

[9] F. D., Bagozzi, R. P., \& Warshaw, P. R. Davis, "A comparison of two theoretical models," in User acceptance of computer technology, vol. 35, 1989, pp. 900-1010.

[10] V., Morris, M. G., Davis, G. B., \& Davis, F. D. Venkatesh, User acceptance of information technology. toward a unified view., 2003.

[11] Fitzgerald, A critical look at open source., 2011.

[12] M., \& Davison, M. Khalifa, "SME adoption of IT: the case of electronic trading," 2006. 
[13] M.M. and Ward, J.M. Caldeira, "Using resource-based theory to interpret the successful adoption and use of information systems and technology in manufacturing small and medium-sized enterprises," European Journal of Information Systems, vol. 12, no. 2, pp. 127-1, 2003.

[14] R., \& Zott, C. Amit, "Value creation in e-business," Strategic Management Journal, vol. 22, pp. 6-7, 2001.

[15] P. J., and Powell, Walter W. DiMaggio, "The iron cage revisited: Institutional isomorphism and collective rationality in organizational fields," American Sociological Review , vol. 48, pp. 147-60, 1983.

[16] E. M. Rogers, "Diffusion of Innovations," Free Press, vol. 5, 2003 .
[17] L., Fleischer, M., \& Chakrabarti, A. Tornatzky, The processes of technological innovation., 1990.

[18] G. Munoz-Cornejo, "An Empirical Investigation into the Adoption of Open Source Software in Hospitals," 2007.

[19] Alsomali S. A., "Electronic Commerce Adoption, A Study of Business-to-Business Practices in Saudi Arabia," 2011.

[20] O Mogire, "Digital Forensics Framework For Kenya Courts of Laws," UoN, Nairobi, 2011.

[21] J.C. Nunnally, Psychometric Theory (2nd Edition). New York: McGraw-Hill, 1978 